\title{
Requisitos de clientes para o desenvolvimento de um implemento a fim de fechar taipas abertas para drenagem
}

\section{Customer requirements for development of an implement for closing levees opened for drainage}

\author{
Ulisses Giacomini Frantz ${ }^{I^{*}}$ José Fernando Schlosser $^{\text {II }}$ Leonardo Nabaes Romano ${ }^{\text {III }}$ \\ Marcelo Silveira de Farias ${ }^{I}$ Fabrício Azevedo Rodrigues ${ }^{I}$
}

\section{RESUMO}

\begin{abstract}
$O$ arroz irrigado é cultivado na maior parte do RS com aplainamento da superficie do solo em desnivel e sistema de cultivo mínimo. Com a semeadura em solo seco, há necessidade de conformar drenos, que cortam transversalmente as taipas, na área de cultivo. Para o estabelecimento da lâmina de água definitiva, essas taipas abertas para drenagem devem ser fechadas e, para essa finalidade, não existe um equipamento especifico que execute tal atividade com devida agilidade e qualidade, sendo necessário o desenvolvimento de um implemento com este fim. Ainda, para o processo de desenvolvimento de máquinas agrícolas, faz-se necessário o levantamento de uma série de informações. $\mathrm{Na}$ fase de projetação, essas informações são necessárias para o estabelecimento das necessidades dos clientes/usuários e dos requisitos dos clientes, para posteriormente serem transformadas em requisitos de projeto e estabelecidas as especificações de projeto. Desse modo, este trabalho objetivou determinar os requisitos dos clientes, a partir das suas necessidades, para o projeto de um implemento com a função de fechamento de taipas abertas para drenagem no arroz irrigado. As informações foram levantadas a partir de pesquisas bibliográficas e aplicação de questionários a futuros clientes/usuários. Como resultados, foram identificadas as necessidades dos clientes, assim como 25 requisitos de clientes.
\end{abstract}

Palavras-chave: arroz irrigado, projeto, eficiência.

\section{ABSTRACT}

The irrigated rice is grown on most part of $R S$ with planning surface on sunken soil and minimum tillage system. With the dry soil sowing there is a need to conform drains, which cut across the levees in the growing area. For the establishment of a definitive water slide, these open for drainage levees must be closed and for this goal there is no specific equipment that execute such activity with agility and quality, being necessary the development of an implement. Still, for the agricultural machinery development process, the raising of a lot of information is required. At the design specification phase, this information is required for the constitution of the customer/ users needs and requirements, in order to be transformed in design requirements and later establish the design specifications. Thereby, this study had the objective of determining the customer requirements, starting from customer needs, to design an implement for closure of open levees for drainage of irrigated rice. All the information was obtained from bibliographic research and questionnaire application to future customers/users. The customer needs, as well as, 25 customer requisites were identified as results.

Key words: irrigated rice, project, efficiency.

\section{INTRODUÇÃO}

O Estado do Rio Grande do Sul (RS) é o maior produtor de arroz irrigado do Brasil, tendo contribuído, na safra 2012/2013, com $67 \%$ da produção nacional (CONAB, 2013). A utilização das áreas de várzea para cultivo do arroz irrigado no Estado do Rio Grande do Sul (RS) é diversificada (MASSONI et al., 2013). A lavoura de arroz no RS se diferencia de outras culturas pela necessidade de tecnificação em seus processos de preparo de solo e cultivo. Dentre estes, está a sistematização da área, que consiste no processo de adequação da superfície natural do terreno, de modo a transformála num plano ou numa superfície plana organizada (PARFITT et al., 1999).

\footnotetext{
IPrograma de Pós-graduação em Engenharia Agrícola (PPGEA), Universidade Federal de Santa Maria (UFSM), 97105-900, Santa Maria, RS, Brasil. E-mail: ulissesgf@hotmail.com. *Autor para correspondência.

IIDepartamento de Engenharia Rural, Centro de Ciências Rurais, UFSM, Santa Maria, RS, Brasil.

IIIDepartamento de Engenharia Mecânica, Centro de Tecnologia, UFSM, Santa Maria, RS, Brasil.
} 
A sistematização com aplainamento da superfície do solo em desnível (SASSD) é predominante nas áreas com cultivo de arroz irrigado no RS, assim como os sistemas de cultivo que utilizam a semeadura em solo seco, como o sistema convencional e cultivo mínimo. Para esse processo de sistematização, que, conforme IRGA (2005), é utilizado em $81,2 \%$ das áreas do RS, após o preparo do solo, é conveniente que se faça o entaipamento. As taipas geradas através desse processo são utilizadas para conter a água de irrigação, sendo conformadas por meio de implementos denominados de entaipadoras.

As culturas em áreas de várzea têm seu comportamento extremamente influenciado pelo manejo, haja vista que estes locais apresentam características químicas e físico-hídricas bastante distintas (SANTOS et al., 1999). A característica comum, dominante nos solos de várzea do RS é a deficiente drenagem natural, devido à topografia predominantemente plana e às suas características físicas (SILVA \& PARFITT, 2004). Por isso, na semeadura em solo seco, há necessidade de ter uma boa drenagem da área, o que é realizado pela conformação de drenos nas áreas de cultivo que cortam as taipas transversalmente e permanecem até o estabelecimento da lâmina de irrigação definitiva. Neste momento, é necessário realizar o fechamento das aberturas realizadas nas taipas, o que é feito pelos produtores utilizando diversos meios não específicos, e tornando-se um processo de baixa capacidade operacional. Assim, necessita-se o desenvolvimento de uma máquina para o fechamento de taipas abertas para drenagem.

O desenvolvimento de máquinas e implementos agrícolas, em geral, advém de uma necessidade, que, muitas vezes, é oriunda do produtor rural, o qual tem grande importância nesse procedimento. Nesse sentido, o processo de desenvolvimento de produtos (PDP), tanto para quem projeta e desenvolve produtos, quanto para empresas, lida com uma dicotomia inseparável, pois deve ser criativo e pragmático (BARBALHO \& ROZENFELD, 2010).

Os modelos de referência podem ser entendidos como diretrizes, procedimentos e critérios de decisão para que ocorra o sucesso no PDP (BARBALHO \& ROZENFELD, 2013). Conforme ROMANO (2013), o processo de desenvolvimento de máquinas é dividido em três macrofases: planejamento, projetação e implementação. A macrofase de projetação caracteriza-se por ser a fase em que o projeto do produto é elaborado. Ainda, conforme o autor, esta fase compreende o projeto informacional, conceitual, preliminar e detalhado. Dentre estas, a fase de projeto informacional tem grande importância e vai desde a busca dos fatores de influência (MARINI \& ROMANO, 2009) até as necessidades dos clientes, que são transformadas em requisitos de clientes e, posteriormente, em requisitos de projeto, os quais geram as especificações de projeto, que serão utilizadas durante o restante do processo de desenvolvimento da máquina.

Quando há possibilidade de geração de um produto novo, necessita-se ter atenção no processo de projeto que será utilizado, isso para que o produto incorpore todos os atributos que são indispensáveis para o cumprimento da tarefa a que se destina (REIS \& FORCELLINI, 2006). Nesse sentido, conforme SCALICE et al. (2012), vários autores relatam a importância de um correto e completo projeto das interfaces de um produto. Ainda, segundo PMI (2004), o projeto é um esforço temporário realizado para criar um novo produto, serviço ou resultado exclusivo.

$\mathrm{O}$ projeto de produto inicia com as informações de mercado e inclui ainda os interesses ou manifestações dos clientes de projeto (necessidades dos clientes), ou seja, daquelas pessoas envolvidas direta ou indiretamente com o projeto ou produto em questão (FONSECA, 2000). Conforme o mesmo autor, essas informações, que geralmente são genéricas e qualitativas, são transformadas em especificações de projeto, ou seja, em requisitos quantitativos, que estabelecem os principais problemas técnicos a serem resolvidos e as restrições de solução. Esse processo de transformação de informação é denominado, segundo FONSECA (2000), de projeto informacional do produto.

As necessidades dos clientes são aquelas características que os clientes desejam que o produto deva ter, que são declarados em uma linguagem distinta da utilizada na engenharia (REIS \& FORCELLINI, 2006). BACK et al. (2008) relatam que a identificação e coleta das necessidades deve ser atendida como primeira prioridade, uma vez que é a atividade que identifica as necessidades do consumidor. Segundo ROZENFELD et al. (2006), inicialmente, as necessidades e demandas dos clientes são organizadas, categorizadas e estruturadas, gerando os requisitos do cliente.

Os requisitos de clientes são a conversão daquela linguagem popular do cliente em linguagem técnica (MENEGATTI, 2004), sendo o entendimento atual das necessidades do cliente e do novo produto, serviço ou resultado que deve satisfazer esses requisitos (PMI, 2004). Conforme BACK et al. (2008), isto facilita a visualização das necessidades 
dos clientes pelos projetistas. Os requisitos fazem inferência a funções, atributos e outras características do produto ou serviço que são requeridos pelo cliente (KAMARA; ANUMBA \& EVBUOMWAN, 2000). Esses requisitos expressam as expectativas, anseios e perspectivas dos clientes acerca de um produto que não existe, refletindo a principal fonte de informação para o projeto.

Com base nessas informações, o objetivo deste trabalho foi apresentar os requisitos de clientes identificados no processo de projeto de um implemento para o fechamento de taipas abertas, utilizadas para drenagem no arroz irrigado.

\section{MATERIAL E MÉTODOS}

Para a obtenção dos requisitos dos clientes, foram utilizadas as atividades do Modelo de Referência para o Processo de Desenvolvimento de Máquinas Agrícolas de ROMANO (2013), mais especificamente, a utilização da fase de projeto informacional da macrofase de projetação. Nessa fase, buscou-se informações referentes aos fatores de influência dentro do projeto, sendo realizadas pesquisas de campo, busca a literaturas diversas (teses, dissertações, artigos científicos, sites de órgãos como o Instituto Rio Grandense do Arroz), informações disponíveis em meios de veiculação, entre outras.

Assim, foram identificados os clientes ao longo do ciclo de vida do produto e, posteriormente, estas informações, juntamente com as anteriores, foram utilizadas para elaboração de um questionário a ser aplicado aos futuros clientes/usuários. O questionário foi aplicado a um grupo homogêneo de 21 respondentes, por meio dos seguintes pré-requisitos de homogeneidade do entrevistado: experiência mínima de 10 anos na atividade; cultivar arroz no sistema SASSD; e conhecer a operação de fechamento de drenos. Os resultados dos questionários, juntamente com as informações levantadas nos fatores de influência, permitiu o estabelecimento das necessidades dos clientes.

Como as necessidades de clientes não podem ser aplicadas diretamente no projeto da máquina, tanto as derivadas de pesquisa bibliográfica quanto as do questionário, elas foram transformadas em características menos abstratas e mais condizentes com a linguagem técnica. $\mathrm{O}$ desdobramento das necessidades dos clientes em requisitos dos clientes foi um trabalho feito em equipe, sendo tais necessidades transformadas em uma linguagem mais compatível com a da engenharia, o que foi realizado por meio de brainstorming. Posteriormente, estes requisitos foram ordenados decrescentemente, conforme importância por meio de diagrama de Mudge. Os requisitos dos clientes, nesse diagrama, foram colocados em uma matriz quadrada, alocandose, nas linhas e nas colunas, os requisitos dos clientes. Assim, foi realizada a comparação de cada requisito da linha, com cada requisito da coluna, atribuindo-se graus de importância conforme a relação entre eles (não é dada valoração quando são comparados os mesmos requisitos). Quando um requisito é pouco mais importante que o outro, recebeu valoração 1 , se medianamente mais importante, valoração 3 , e se for muito mais importante, recebe valoração 5. Após o somatório dos pontos obtidos para cada requisito, dentre todas as comparações efetuadas, tem-se a ordem de importância em função dos maiores valores.

\section{RESULTADOS E DISCUSSÃO}

Em função do questionário elaborado, para os futuros clientes/usuários, conter 30 questões e ocupar um grande espaço neste artigo, este será apresentado parcialmente, conforme é ilustrado na tabela 1. Com base nas respostas obtidas na aplicação do questionário, pode-se identificar algumas tendências.

A primeira é que tenha baixo custo e que tenha um sistema de acoplamento que provoque poucos danos à cultura. Ainda, para proporcionar uma maior rapidez durante a operação da máquina e, consequentemente provocar poucos danos à cultura implantada (retirar a menor quantidade possível de plântulas de arroz), ainda, ela deve ser acoplada ao sistema hidráulico de três pontos do trator.

Para a retirada de solo, que vai ser utilizado para realizar o fechamento, a maioria dos respondentes revelou que este deve ser retirado da própria lavoura, proveniente do leiveiro e da própria taipa e que seja retirado superficialmente. Esses fatores fazem com que o elemento que irá proporcionar a retirada de solo tenha que atender a essas características. Ainda, a regulagem do implemento deve proporcionar que o elemento projetado possa ser ajustado ao formato da taipa. Por último, após o fechamento da abertura realizada na taipa, não deve proporcionar seu rompimento após a entrada da água de irrigação definitiva.

Corroborando com os resultados obtidos, LIMA et al. (2011) afirmam que é necessário captar as necessidades e expectativas não explicitadas pelo cliente final para que essas informações sejam 
Tabela 1- Questionário parcial aplicado aos futuros clientes/usuários.

\begin{tabular}{|c|c|}
\hline Questionamento & Resumo das respostas \\
\hline $\begin{array}{l}\text { 1. Qual perfil profissional melhor relaciona o seu } \\
\text { conhecimento acerca de equipamentos para } \\
\text { fechamento de drenos superficiais em lavouras } \\
\text { de arroz irrigado? }\end{array}$ & $\begin{array}{l}\text { Projetista de máquinas e implementos; engenheiro }(4,76 \%) \text {; vendedor de máquinas e } \\
\text { implementos agrícolas }(0 \%) \text {; engenheiro de produção de máquinas e implementos } \\
\text { agrícolas }(4,76 \%) \text {; agricultor (produtor rural) }(52,38 \%) \text {; operador de máquinas } \\
\text { agrícolas }(19,05 \%) \text {; Professor }(9,52 \%) \text {; extensionista }(4,76 \%) \text {; pesquisador }(9,52 \%) \text {; } \\
\text { outro }(0 \%)\end{array}$ \\
\hline
\end{tabular}

5. Numere de acordo com o grau de importância o que você acha mais importante que o implemento tenha:

Preço baixo $\left(6^{\circ}\right)$; funcionalidade $\left(7^{\circ}\right)$; forma, modelo, leiaute $\left(10^{\circ}\right)$; desempenho operacional elevado (rapidez no serviço efetuado) $\left(2^{\circ}\right)$; baixo custo na reposição de peças $\left(8^{\circ}\right)$; qualidade final do serviço efetuado $\left(1^{\circ}\right)$; Segurança $\left(9^{\circ}\right)$; durabilidade $\left(4^{\circ}\right)$; agilidade $\left(3^{\circ}\right)$; fácil regulagem $\left(5^{\circ}\right)$.

6. Quanto ao preço do produto, ele deveria estar na faixa de:

Mais de $\mathrm{R} \$ 20.000(0 \%)$; entre $\mathrm{R} \$ 15.001$ e $\mathrm{R} \$ 20.000(9,52 \%)$; entre $\mathrm{R} \$ 10.001$ e $\mathrm{R} \$ 15.000$ (23,81\%); entre $\mathrm{R} \$ 5.001$ e $\mathrm{R} \$ 10.000$ (52,38\%); entre $\mathrm{R} \$ 1.000$ e $\mathrm{R} \$$ $5.000(14,29 \%)$; outro $(0 \%)$.

8. O equipamento deve ter um sistema de acoplamento que possibilite:

Menores danos à cultura (52,38\%); maior capacidade operacional (4,76\%); melhor qualidade do serviço efetuado $(42,86 \%)$; seja mais barata $(0 \%)$.

10. Quanto ao desempenho operacional você considera:

Muito importante $(95,24 \%)$; medianamente importante $(4,76 \%)$; sem importância $(0 \%)$.

Que a qualidade do fechamento do dreno seja semelhante ao perfil anteriormente

14. Quanto à realização da operação de fechamento de drenos, necessita-se:

existente ao do dreno (que seja da mesma altura da taipa) $(0 \%)$; que a qualidade do fechamento do dreno permita que a taipa não rompa após a entrada da água na lavoura (100\%); não interessa $(0 \%)$; outro, especifique $(0 \%)$.

16. De onde deve ser retirada a quantidade de solo que irá preencher o dreno?

De dentro da lavoura $(95,24 \%)$; de áreas adjacentes à lavoura $(0 \%)$; de outro local $(4,76 \%)$.

17. Se a quantidade de solo retirada para fechamento do dreno for de dentro da lavoura, qual o local mais apropriado?

De dentro do quadro $(4,76 \%)$; da taipa $(28,57 \%)$; da ronda da lavoura $(0 \%)$; do leiveiro $(71,43 \%)$; outro $(0 \%)$

18. A quantidade de solo deve ser retirada:

Superficialmente $(90,48 \%)$; subsuperficialmente $(4,76 \%)$; outra $(0 \%)$.

20. A quantidade de solo retirada deve:

Permitir que seja retirada a menor quantidade possível de plântulas de arroz da área de dentro da lavoura $(90,48 \%)$; permitir que não sejam retiradas plântulas de arroz da área de dentro da lavoura (4,76\%); não interessa $(4,76)$; outro $(0 \%)$.

27. Se o equipamento fosse acoplado ao trator, De arrasto $(0 \%)$; sistema hidráulico de 3 pontos $(100,00 \%)$; semi montado $(0 \%)$; como deveria ser a forma de acoplar.

TDP $(0 \%)$; não interessa $(0 \%)$; outro $(0 \%)$

28. Regulagem do equipamento para o Ajuste do formato de fechamento $(71,43 \%)$; apenas 1 posição de ajuste $(0 \%)$; não fechamento deve proporcionar interessa o formato de fechamento do dreno (28,57\%); outro (0).

capazes de fornecer subsídios para os tomadores de decisão na concepção e no projeto do produto. Isso torna o produto mais condizente com a realidade do que o cliente espera.

Conforme BACK et al. (2008), no caso de entrevistas com futuros usuários do produto, um número de 20 a 30 entrevistas em um grupo homogêneo de usuários pode garantir que $90 \%$ ou mais das necessidades dos usuários sejam identificadas. Essas necessidades dos clientes, desdobradas em requisitos de clientes, são ilustradas na tabela 2 e, com base nos dados obtidos e sua ordem de importância, pode-se estabelecer uma série de informações relevantes que são listadas a seguir.

$\mathrm{O}$ requisito dos clientes que recebeu maior valoração foi "taipa não deve romper quando efetuada a irrigação", isto se deve à qualidade final do serviço efetuado, pois independentemente de como o solo será colocado na abertura da taipa, ele deve ter quantidade e suficiente para que não seja rompida.

$\mathrm{O}$ segundo requisito que deve ser atendido é "retirar solo de dentro da própria lavoura, próxima

Ciência Rural, v.45, n.4, abr, 2015. 
Tabela 2 - Requisitos dos clientes obtidos a partir das suas necessidades.

\begin{tabular}{|c|c|c|c|c|}
\hline № & Necessidades dos clientes & № & Requisitos dos clientes & Ord. Req.Mudge \\
\hline \multirow{2}{*}{1} & \multirow{2}{*}{ Qualidade final do serviço efetuado } & 1.1 & Preencher a abertura realizada na taipa. & 9 \\
\hline & & 1.2 & Taipa não deve romper quando efetuada a irrigação & 1 \\
\hline \multirow{2}{*}{2} & \multirow{2}{*}{ Desempenho operacional elevado } & 2.1 & Realizar a operação com velocidades de deslocamento elevadas & 13 \\
\hline & & 2.2 & Efetuar o processo de fechamento das aberturas com rapidez & 7 \\
\hline \multirow[t]{2}{*}{3} & \multirow[t]{2}{*}{ Eficiência na operação } & 3.1 & $\begin{array}{l}\text { Proporcionar poucas manobras durante operação do } \\
\text { implemento }\end{array}$ & 21 \\
\hline & & 4.1 & Ter projeto simples & 18 \\
\hline \multirow[t]{2}{*}{4} & \multirow[t]{2}{*}{ Simplicidade e durabilidade } & 4.2 & Ter componentes com baixo desgaste & 24 \\
\hline & & 4.3 & Ter estrutura resistente e componentes com elevada vida útil & 19 \\
\hline \multirow{3}{*}{5} & \multirow{3}{*}{ Fácil regulagem e operação } & 5.1 & Ter fácil regulagem & 16 \\
\hline & & 5.2 & Ter dirigibilidade & 14 \\
\hline & & 6.1 & Ter baixo preço de aquisição & 15 \\
\hline \multirow[t]{2}{*}{6} & \multirow[t]{2}{*}{ Baixo custo de aquisição } & 6.2 & Ter processo de fabricação de baixo custo & 17 \\
\hline & & 6.3 & Ser composta por elementos com baixo custo & 22 \\
\hline 7 & Funcionalidade & 7.1 & Fechar as aberturas realizadas nas taipas & 3 \\
\hline 8 & Segura & 8.1 & Ter mecanismo para suportar o implemento quando parado & 10 \\
\hline 9 & Baixa reposição de peças & 9.1 & Evitar no projeto elementos que necessitem reposição & 12 \\
\hline \multirow{4}{*}{10} & \multirow{4}{*}{$\begin{array}{l}\text { Utilize componentes facilmente } \\
\text { substituíveis }\end{array}$} & 10.1 & Ter grande número de peças encontradas no mercado & 23 \\
\hline & & 10.2 & Ter componentes padronizados & 11 \\
\hline & & 10.3 & Ter baixo tempo de manutenção & 25 \\
\hline & & 10.4 & Ter tempo entre manutenções longo & 20 \\
\hline 11 & $\begin{array}{l}\text { Cause poucos danos à cultura } \\
\text { implantada }\end{array}$ & 11.1 & $\begin{array}{l}\text { Ter elementos para retirada de solo que provoquem poucos } \\
\text { danos à cultura implantada }\end{array}$ & 4 \\
\hline \multirow{2}{*}{12} & \multirow{2}{*}{$\begin{array}{l}\text { Retire solo superficialmente e de } \\
\text { dentro da lavoura }\end{array}$} & 12.1 & $\begin{array}{l}\text { Retirar solo para preenchimento da abertura na taipa } \\
\text { superficialmente }\end{array}$ & 5 \\
\hline & & 12.2 & $\begin{array}{l}\text { Retirar solo de dentro da própria lavoura, próxima ao dreno e } \\
\text { proveniente do leiveiro da taipa }\end{array}$ & 2 \\
\hline \multirow{2}{*}{13} & \multirow{2}{*}{$\begin{array}{l}\text { Seja acoplada ao sistema de } 3 \text { pontos } \\
\text { do trator }\end{array}$} & 13.1 & Ser acoplada a um trator agrícola & 6 \\
\hline & & 13.2 & Ser acoplada através do sistema de engate de 3 pontos & 8 \\
\hline
\end{tabular}

ao dreno e proveniente do leiveiro da taipa", o que foi estabelecido pelos clientes no questionário estruturado, e deve-se ao fato de que esta área da lavoura muitas vezes possui uma menor produtividade que as demais.

Deve ser prevista uma forma, conforme o quarto requisito, para "ter elementos para retirada de solo que provoquem poucos danos à cultura implantada”, ou seja, que estes elementos não provoquem amassamento, corte excessivo das plantas cultivadas, ou outros tipos de danos. Isto pode ser realizado com a limitação da área superficial de solo retirada, contrapondo-o com a profundidade de retirada, que, conforme o quinto requisito, este deve ser retirado superficialmente da área. O contexto de evitar danos à espécie de cultivo implantada foi considerado por ALBIERO, MACIEL \& GAMERO (2011) no projeto e desenvolvimento de uma colhedora de babaçu, sendo de grande importância.

O sexto requisito, "ser acoplada a um trator agrícola", aliado ao oitavo requisito, "Ser acoplada através do sistema de engate de 3 pontos" descrevem as necessidades dos clientes transformadas em requisitos. Esses dois são a base fundamental para o estabelecimento de etapas posteriores de projetação, pois, dependendo da categoria de engate de três pontos do trator a ser utilizado, as dimensões do elemento que irá realizar o acoplamento da máquina à fonte de potência serão diferentes.

Embora todas as características sejam necessárias, SANTOS et al. (2008) também verificaram que os requisitos apresentam grau de importância diferenciado, e que devem ser levado s em consideração nas fases de projetação.

O sétimo, "efetuar o processo de fechamento das aberturas com rapidez”, é necessário para que o implemento tenha viabilidade a campo e elevada capacidade operacional. Para isso, devem-se prever elementos que tenham pouca complexidade durante a operação e fácil regulagem. Nesse sentido, "preencher a abertura realizada na taipa" (9o) descreve a necessidade de que o implemento seja 
capaz de preencher, com uma quantidade adequada de solo, a abertura contida na taipa. Portanto, esse requisito deve ser atendido com base nas dimensões de taipas proporcionadas pelas entaipadoras disponíveis atualmente, além de saber quais as dimensões do dreno formado na área e, a partir destas características, poder calcular a quantidade de solo que deve ser utilizado.

O décimo "ter mecanismo para suportar o implemento quando parado" e o décimo primeiro "ter componentes padronizados" são requisitos que devem ser atendidos, porém, dependendo do nível de complexidade intrínseco ao desenvolvimento do projeto, alguns elementos podem não atendêlo, sendo que isso influencia diretamente o décimo segundo requisito "evitar no projeto elementos que necessitem reposição".

A posição ocupada pelo décimo quinto requisito "ter baixo preço de aquisição" devese ao fato de que, para o produtor, nada adianta um implemento com baixo preço, se não realiza eficientemente sua função. Se este implemento possuir um baixo preço de aquisição e executar a função, porém de alta complexidade e dispêndio de tempo, não terá a funcionalidade que necessita para efetuar o fechamento das aberturas com rapidez.

Os requisitos que poderão influenciar de alguma forma o décimo quinto requisito ("ter baixo preço de aquisição") são: 19o "ter estrutura resistente e componentes com elevada vida útil", 17 o "ter processo de fabricação de baixo custo", 20 o "ter tempo entre manutenções longo", 22 "ser composta por elementos com baixo custo", 23 "ter grande número de peças encontradas no mercado", 24 "ter componentes com baixo desgaste". Além disso, cada um destes requisitos deve ser avaliado de forma a contribuir positivamente no projeto de desenvolvimento do implemento agrícola. Essa necessidade de minimização do custo também foi verificada por trabalhos realizados por SCALICE et al. (2012) e REIS \& FORCELLINI (2006).

Para os requisitos 13 "realizar a operação com velocidades de deslocamento elevadas", 14 "ter dirigibilidade" e 21ㅇ "proporcionar poucas manobras durante a operação do implemento" devem ser observados os requisitos que dizem respeito ao acoplamento do implemento ao trator agrícola e ao seu sistema hidráulico de três pontos.

Os requisitos 16ㅇ "ter fácil regulagem" e 17 0 "ter projeto simples" são necessários para adequar a máquina à situação em campo e para reduzir a complexidade do projeto, respectivamente. Esses dois requisitos de clientes também foram identificados por
REIS \& FORCELLINI (2006) para o projeto de um dosador de precisão de sementes miúdas. O 20 "ter tempo entre manutenções longo" significa o tempo entre uma manutenção e outra, devendo ser previsto poucos elementos que necessitem de manutenção, e o vigésimo quinto "ter baixo tempo de manutenção", para que esse tempo não seja um fator limitante no campo.

\section{CONCLUSÃO}

O modelo de referência utilizado, e sua metodologia, facilitou o processo de aquisição de informações para o estabelecimento dos requisitos de clientes.

A análise das necessidades dos clientes permitiu identificar 25 requisitos destes, que abrangem o que realmente é necessário para a operação de fechamento de taipas abertas para drenagem. Ainda, os requisitos mais importantes para o desenvolvimento do implemento são: "evitar rompimento da taipa quando efetuada a irrigação"; "retirar solo de dentro da própria lavoura, próxima ao dreno e proveniente do leiveiro da taipa"; "fechar as aberturas realizadas nas taipas".

\section{AGRADECIMENTOS}

Os autores agradecem ao apoio financeiro recebido da Coordenação de Aperfeiçoamento de Pessoal de Nível Superior (CAPES) e Conselho Nacional de Desenvolvimento Científico e Tecnológico (CNPq). Também, ao CNPq pela bolsa de produtividade em pesquisa do segundo autor.

\section{REFERÊNCIAS}

ALBIERO, D.et al. Desenvolvimento e projeto de colhedora de babaçu (Orbignya phalerata Mart.) para agricultura familiar nas regiões de matas de transição da Amazônia. Acta Amazonica, v.41, n.1, p.57-68, 2011. Disponível em: <http://dx.doi.org/10.1590/ S0044-59672011000100007>. Acesso em: 08 set. 2014. doi: 10.1590/S0044-59672011000100007.

BACK, N. et al. Projeto integrado de produtos: planejamento, concepção e modelagem. Barueri: Manole, 2008. 601p.

BARBALHO, S.C.M.; ROZENFELD, H. O impacto dos aspectos organizacionais sobre a percepção de melhoria em desenvolvimento de produtos. Gestão \& Produção, v.17, n.1, p.1-17, 2010. Disponível em: <http://dx.doi.org/10.1590/S0104530X2010000100002>. Acesso em: 08 set. 2014. doi: 10.1590/ S0104-530X2010000100002.

BARBALHO, S.C.M.; ROZENFELD, H. Modelo de referência para o processo de desenvolvimento de produtos mecatrônicos (MRM): validação e resultados de uso. Gestão \& Produção, v.20, n.1, p.162-179, 2013. Disponível em: <http://dx.doi.org/10.1590/ S0104-530X2013000100012>. Acesso em: 08 set. 2014. doi: 10.1590/S0104-530X2013000100012. 
CONAB (COMPANHIA NACIONAL DE ABASTECIMENTO). Acompanhamentoda Safra Brasileira de Grãos. Décimo Segundo Levantamento - Setembro de 2013. Disponível em: <http://www.conab.gov.br/OlalaCMS uploads/arquivos/13_09_10_16_05_53_boletim_portugues_ setembro 2013.pdf>. Acesso em: 08 set. 2014.

FONSECA, A.J.H. Sistematização do processo de obtenção das especificações de projeto de produtos industriais e sua implementação computacional. 2000. 199f. Tese (Doutorado em Engenharia Mecânica) - Universidade Federal de Santa Catarina,Florianópolis, SC

IRGA (INSTITUTO RIO GRANDENSE DO ARROZ). Censo da lavoura de arroz irrigado do Rio Grande do Sul - Safra 2004-2005. Porto Alegre, 2005. Disponível em: <http://www3. irga.rs.gov.br/uploads/anexos/1292592973censodg3.pdf>. Acesso em: 08 set. 2013

KAMARA, J.M et al. Establishing and processing client requirements: a key aspect of concurrent engineering in construction. Engineering, Construction and Architectural Management, v.7, n.1, p.15-28, 2000. Disponível em: <http:/ dx.doi.org/10.1108/eb021129>. Acesso em: 08 set. 2014. doi: 10.1108/eb021129.

LIMA, L.P. et al. Proposta de um protocolo para o processamento de requisitos do cliente em empreendimentos habitacionais de interesse social. Ambiente Construído, v.11, n.2, p.2137, 2011. Disponível em: <http://dx.doi.org/10.1590/S1678$86212011000200003>$. Acesso em: 08 set 2014. doi: 10.1590/ S1678-86212011000200003.

MARINI, V.K.; ROMANO, L.N. Influencing factors in agricultura machinery design. Product (IGDP), v.07, p.111-130, 2009. Disponível em: <pmd.hostcentral.com.br/revistas/vol_07/nr_2/ v7n2a7203.pdf>. Acesso em: 08 set. 2014.

MASSONI, P.F.S.et al. Influência de manejos pós-colheita do arroz irrigado sobre o banco de sementes de arroz-vermelho. Planta Daninha, v.31, n.1, p.89-98, 2013. Disponível em: <http://www. scielo.br/pdf/pd/v31n1/10.pdf $>$. Acesso em: 08 set. 2014. doi 10.1590/S0100-83582013000100010

MENEGATTI, F.A. Desenvolvimento de um sistema de dosagem de fertilizantes para agricultura de precisão. 2004. $296 \mathrm{f}$ Dissertação (Mestrado em Engenharia Mecânica) - Universidade Federal de Santa Catarina, Florianópolis, SC.
PARFITT, J.M.B. et al. Sistematização de solos de várzea. In: GOMES, A. da S.; PAUlletTO, E. (Ed.). Manejo do solo e da água em áreas de várzea. Pelotas: Embrapa Clima Temperado, 1999. p.37-60.

PMI (PROJECT MANAGEMENT INSTITUTE). Um guia do conjunto de conhecimentos em gerenciamento de projetos: guia PMBOK. 3. ed. Pennsylvania: Four Campus Boulevard, 2004. 389 p.

REIS, A.V.; FORCELLINI, F.A. Identificação de requisitos de clientes para o projeto de umdosador de precisão para sementes miúdas. Engenharia Agrícola, v.26, n.1, p.309-320, jan./ abr. 2006.Disponível em: <http://dx.doi.org/10.1590/S010069162006000100033>. Acesso em: 08 set. 2014. doi: 10.1590/ S0100-69162006000100033.

ROMANO, L.N. Desenvolvimento de máquinas agrícolas: planejamento, projeto e produção. São Paulo: Blucher Acadêmico, 2013. 310p.

ROZENFELD, $H$. et al.Gestão de desenvolvimento de produtos: uma referência para a melhoria do processo. São Paulo: Saraiva, 2006. 542p.

SANTOS, A.B. et al. Manejo de água e de fertilizante potássico na cultura de arroz irrigado. Pesquisa agropecuária brasileira, v.34, n.4, p.565-573, 1999. Disponível em: <http://dx.doi.org/10.1590/ S0100-204X1999000400007>. Acesso em: 08 set. 2014. doi: 10.1590/S0100-204X1999000400007.

SANTOS, P.M. et al.Prioridades de requisitos para projeto de postos de operaçãode tratores quanto à ergonomia e segurança. Pesquisa agropecuária brasileira, v.43, n.7, p.869-877, 2008. Disponível em: <http://dx.doi.org/10.1590/S0100204X2008000700011>. Acesso em: 08 set. 2014. doi: 10.1590/ S0100-204X2008000700011

SCALICE, R.K. et al.Procedimento para seleção de interfaces para produtos modulares baseado no ciclo de projeto de produtos. Produção, v.22, n.4, p.734-750, 2012. Disponível em: <http:// dx.doi.org/10.1590/S0103-65132012005000085>. Acesso em: 08 set. 2014. doi: 10.1590/S0103-65132012005000085

SILVA, C.A.S.; PARFITT, J.M.B. Drenagem superficial para diversificação do uso de várzea do Rio Grande do Sul. Pelotas: Embrapa Clima Temperado, 2004. 10p. (Embrapa Clima Temperado. Circular Técnica, 40) 